associated with compliance but failed to introduce this concept of 'concordance', which has been advocated as a more collaborative, consensual, psycho-educational term (Mullen, 1997). Likewise although the importance and impact on non-compliance is described, Buchanan's work in asserting that compliance in schizophrenia is no worse than in any other chronic medical disorder (Buchanan, 1996) was not mentioned. The notion that people with schizophrenia form part of a general medical population where compliance is a challenge helps prevent the negative labelling of people with mental disorders as poor compliers. This is surely part of reducing the stigma of mental illness.

Buchanan, A. (1996) Compliance with Treatment in Schizophrenia. Maudsley Monograph no. 37. London: Psychology Press.

MULLEN, P. D. (1997) Compliance becomes concordance. British Medical Journal, $\mathbf{3 1 4}$.

C. J. HALEY, Senior Registrar in Adult Psychiatry, University of Liverpool, Department of Clinical Psychology, The Whelan Building, Quadrangle, Brownlow Hill, Liverpool L69 3GB

\section{Body decoration and intravenous drug misuse}

Sir: Williams (Psychiatric Bulletin, January 1998, 22, 94-96) describes tattoos and body adornment among psychiatric admissions. We surveyed an opportunistic sample of 50 drug users attending a community drug team, systematically recording details of tattoos, tattooing practice and body piercing. The sample comprised 41 men and nine women, with an average age of 28.9 years. Forty-four had histories of intravenous drug use.

The maximum number of tattoos was 20 in women and 25 in men. Thirty-two subjects had tattoos of real or mythical animals, 30 were tattooed with family member's names, 27 with their own first name, 11 with their own nickname, and nine with gang names. Sixteen were tattooed with drug-related names or pictures: cannabis leaves, syringes and psilocybin mushrooms being the most common. Twenty-eight men and two women had been tattooed in prison.

Forty-six subjects had pierced ears, seven a pierced nose, five men and one woman pierced nipples, and three men pierced genitals. The maximum number of piercings was 16 in men and 13 in women. Sixteen drug injectors with piercings had failed to use basic sterile precautions when body piercing, whereas all six noninjectors had always used aseptic techniques.
That drug injectors are less careful about sterile technique during body piercing must cause concern.

BERNADETTE CANTWELL, formerly medical student, C/O Community Addiction Unit, Whitchurch Hospital, Cardiff CF4 7XB; JULIAN H. RACE, Consultant Psychiatrist, North Wales Hospital, Denbigh LL16 5SS; and ANDREW J. MCBRIDE, Community Addiction Unit, Whitchurch Hospital, Cardiff CF4 7XB

\section{Research by senior registrars in psychiatry}

Sir: Williams \& Curran (Psychiatric Bulletin, February 1998, 22, 102-104) draw a number of conclusions from their questionnaire survey, which they feel may be helpful and relevant to the training needs of specialist registrars. However, their data may support other conclusions. I note that only one-third of respondents admitted to performing research for their own interest; the other two-thirds were apparently motivated for 'curriculum vitae' purposes, to 'advance career' or even to 'please others'.

My experience is that many higher trainees have an extremely ambivalent attitude towards research. While recognising the necessity of being able to critically analyse research, many trainees have no intention of performing research as a consultant (and probably will not have the time), yet feel compelled to 'go through the motions' of (at least appearing) to conduct research, as this is expected of them. If the research is completed (and with poor motivation, much is not), it is often of poor quality and of little clinical use.

If there are lessons to be learnt from the senior registrar grade, then perhaps encouraging and facilitating higher trainees to use their study day in a way which would be most useful to them as individuals (taking into account their career plans) should be one. Surely it is time to stop trying to force too many square pegs into the round (black) holes of research.

DAVID LAWLEY, Senior Registrar in Psychiatry, Bootham Park Hospital, York YO3 7BY

\section{Work of the Mental Health Act Commission}

Sir: We were surprised by the letter from Tyrer and colleagues (Psychiatric Bulletin. February 1998, 22, 118-119), and cannot agree with their criticisms of the work of the Mental Health Act Commission. We do not see that either the increased pressure on beds or the introduction of new statutory review procedures makes the 